\title{
Contribuições para uma Formação em Psicologia Integrada à Política de Assistência Social
}

\author{
Simone Maria Hüning ${ }^{1}$ \\ ${ }^{1}$ Universidade Federal de Alagoas, AL, Brasil.
}

\author{
Érika Cecília Soares Oliveira ${ }^{1}$ \\ ${ }^{1}$ Universidade Federal de Alagoas, AL, Brasil.
}

Resumo: Neste trabalho objetiva-se compartilhar e analisar uma experiência de ensinoaprendizagem que buscou articular a formação acadêmica de estudantes de graduação em psicologia com a formação profissional de trabalhadores(as) da Política Nacional de Assistência Social, configurando-se simultaneamente como processo político-pedagógico e de intervenção. A experiência foi desenvolvida no âmbito de uma disciplina do curso de graduação em psicologia de uma universidade federal no Nordeste do Brasil, considerando preceitos relativos à prática da extensão universitária como ação política e epistemológica da universidade, bem como a Política Nacional de Formação Permanente do Sistema Único de Assistência Social. Utilizamos uma metodologia dialógica de construção do trabalho, que passou por várias etapas de negociação envolvendo docentes, gestores(as), discentes e trabalhadores(as), que é aqui apresentada. Os encontros realizados foram marcados pela indissociabilidade entre prática e teoria. As reflexões evidenciaram a importância da qualificação e politização das práticas de ensino-aprendizagem da psicologia e da atuação de profissionais inseridos(as) na política de assistência social. Do mesmo modo, pontuou-se as complexidades que caracterizam o trabalho com populações que vivem em situações de desigualdade e exclusão social, detendo-se nas especificidades do contexto brasileiro e local, com a abordagem de questões como a racialização e generificação da pobreza. A avaliação da experiência realizada nos permite afirmar que é possível fazer da sala de aula um espaço de compartilhamento de práticas e saberes, integrado aos campos de exercício profissional, com a criação de processos de aprendizagem contrahegemônicos com relação às perspectivas tradicionais, fazendo de todos(as) copartícipes de sua própria formação.

Palavras-chave: Psicologia, Formação, Desobediência epistêmica, Política pública de assistência social.

\section{Contributions to the Formation in Psychology Integrated to the Social Assistance Policy}

\begin{abstract}
In this work, we intend to share and analyze a teaching-learning experience that tried to articulate the academic formation of undergraduates in Psychology with the professional formation of workers of the Social Assistance National Policy, configuring itself simultaneously as a political-pedagogic and an intervention process. The experience was developed within a discipline of the Psychology undergraduate course in a federal university in Brazil Northeast region, considering precepts related to the practice of university extension as political and epistemological action, and to the National Policy of Permanent Education of the Unified Social Assistance System. We used a dialogical methodology to construct the work, which entailed several negotiation stages involving teachers, managers, students, and workers, as shown in this text. The meetings were marked by the indissociability between practice and theory.
\end{abstract}


The reflections highlighted the importance of qualification and politicization of teachinglearning practices in Psychology and of the action of workers inserted in the social assistance policy. Likewise, they pointed out the complexities that characterize the work with populations that live in situation of inequality and social exclusion, concentrating on the specificities of both Brazilian and local contexts, approaching issues such as racialization and gendering of poverty. The evaluation of the experience carried out allows us to state that turning the classroom into a space for sharing practices and knowledges, integrated to the fields of professional practice, with the creation of counter-hegemonic learning processes against the traditional perspectives, making everyone co-participant in their own education, is possible.

Keywords: Psychology, Education, Epistemic disobedience, Social assistance public policy.

\title{
Contribuciones a la Formación en Psicología Integrada con la Política de Asistencia Social
}

\begin{abstract}
Resumen: Este trabajo tiene por objetivo compartir y analizar una experiencia de enseñanzaaprendizaje que buscó articular la formación académica de estudiantes de pregrado en psicología con la formación profesional de los/as trabajadores/as de la Política Nacional de Asistencia Social, configurándose simultáneamente como proceso político-pedagógico y de intervención. Se desarrolló la experiencia en una asignatura en el curso de pregrado de psicología en una universidad federal en el Nordeste de Brasil, considerando los supuestos relacionados con la extensión universitaria como acción política y epistemológica de la universidad, así como Política Nacional para la Formación Continua del Sistema Unificado de Asistencia Social. Se aplicó una metodología dialógica de construcción del trabajo, que pasó por varias etapas de negociación con la participación de maestros/as, gerentes, estudiantes y trabajadores/as. Los encuentros realizados estuvieron marcados por la inseparabilidad entre la práctica y la teoría. Las reflexiones mostraron la importancia de calificar y politizar las prácticas de enseñanzaaprendizaje de la psicología y la acción de profesionales insertados en la política de asistencia social. Asimismo, se resaltaron las complejidades que caracterizan el trabajo con poblaciones que viven en situaciones de desigualdad y exclusión social, centrándose en las especificidades del contexto brasileño y local, abordando cuestiones como la racialización y la generificación de la pobreza. La evaluación de la experiencia realizada nos permite afirmar que es posible hacer de las clases un espacio para compartir prácticas y conocimientos, integrado con los campos de la práctica profesional, con la creación de procesos de aprendizaje contrahegemónicos a las perspectivas tradicionales, haciendo de todos/as coparticipantes en su propia formación.
\end{abstract}

Palabras clave: Psicología, Formación, Desobediencia epistémica, Política pública de asistencia social.

Neste trabalho, objetivamos compartilhar e analisar uma experiência de ensino-aprendizagem que buscou articular a formação acadêmica de estudantes de graduação em psicologia com a formação profissional de trabalhadores(as) da Política Nacional de Assistência Social, configurando-se simultaneamente como processo político-pedagógico e de intervenção. A proposta surge no âmbito da disciplina Intervenções Psicológicas em Processos Socioculturais, componente curricular obrigatório do curso de psicologia de uma universidade federal brasileira situada na região Nordeste do país, e amplia-se, posteriormente, para outra disciplina e ação de extensão, além de estágio curricular.

Iniciamos apresentando uma contextualização de como limitações e insatisfações vivenciadas no cotidiano do ensino da disciplina nos conduziram a 
sua reformulação e consequente aproximação com a Secretaria Municipal de Assistência Social (Semas), o que permitiu sua realização simultânea como curso de extensão para trabalhadores(as) dessa política. Em seguida, apresentamos a experiência realizada e a colocamos em análise a partir de seus desdobramentos e das avaliações realizadas pelos(as) participantes ao término de cada período de sua realização. Por fim, discutimos potencialidades e limites do trabalho realizado, defendendo que podemos inverter a lógica ensino-aprendizagem com uma recusa pedagógica ao "dar aulas" e uma aposta na construção coletiva do conhecimento e na sala de aula enquanto espaço de compartilhamento de experiências e saberes entre acadêmicos(as) e sociedade. Tal proposta ampara-se na ideia de desaprender aquilo que convencionalmente temos compreendido ser a relação professores(as)/alunos(as), desierarquizando-as numa prática de desobediência epistêmica (Mignolo, 2008) e, consequentemente, acadêmica, ancorada em perspectivas de descolonização dos saberes e dos seres (Arias, 2010; Bernardino-Costa, Maldonado-Torres, \& Grosfoguel, 2019).

\section{Contextualização da proposta}

O curso de psicologia no qual está inserida essa experiência tem como uma de suas ênfases os processos socioculturais. A abrangência do termo coloca, por um lado, uma ampla gama de possibilidades de ênfases de estudos, porém, por outro, pode produzir uma dispersão sobre o modo de abordar esses processos. Demarcarmos essa dispersão como um primeiro elemento que nos conduz à proposta da experiência compartilhada neste trabalho.

$\mathrm{O}$ segundo elemento remete ao fato de que o conjunto de disciplinas que compõem essa ênfase contempla a Intervenções Psicológicas em Processos Socioculturais, que tem como ementa a abordagem prática de projetos de intervenção psicossociais. Contudo, apesar dessa menção à abordagem prática, não há necessariamente inserção de estudantes, nesse momento do curso, em campos de prática onde possam efetivamente desenvolver atividades de intervenção, o que gera certo impasse quanto à viabilidade de efetivação daquilo que a disciplina propõe.

Após vários anos de trabalho como docente dessa disciplina, de inquietações frente às questões inicialmente pontuadas, dos compromissos da universidade pública frente à sociedade e da realidade social e econômica da região em que está inserida essa universidade, entendeu-se que seria pertinente a abordagem dos processos socioculturais de modo articulado às políticas públicas, especialmente à Política Nacional de Assistência Social (PNAS). Tal encaminhamento contemplou a delimitação de um foco mais definido, social e academicamente relevante, porém, não resolvia o impasse relativo à prática das intervenções.

Assim, como estratégia pedagógica, inicialmente, eram realizadas aproximações dos(as) estudantes com os serviços da PNAS, bem como exercícios de elaboração de projetos de intervenção psicossociais a partir da realização de visitas técnicas e, eventualmente, da participação de profissionais nas atividades das disciplinas. Sem dúvida, tais iniciativas ao mesmo tempo em que permitiram uma maior proximidade com o contexto das políticas públicas, complexificaram as discussões e ampliaram as aprendizagens no âmbito da disciplina. Porém, a separação dos espaços e das tarefas (as aulas na universidade onde ocorriam as discussões teóricas e as visitas aos serviços onde se conhecia a experiência) permanecia como um incômodo não solucionado.

$\mathrm{O}$ ir e vir de estudantes e profissionais entre universidade e serviços configurava momentos de trocas que embora fossem ricas, eram também pontuais e limitadas, pouco promotoras de uma construção conjunta e horizontal de saberes. A docente permanecia no espaço acadêmico, facilitando discussões com estudantes, sem alcance aos serviços. Os(As) profissionais dos serviços acolhiam discentes em visitas, mas pouco sabiam do que se produzia na universidade a partir desses encontros. Os textos acadêmicos sobre a PNAS eram estudados, buscando-se uma conexão com a realidade, mas frequentemente esbarravam em uma dificuldade: o desconhecimento ou distanciamento do cotidiano de vida e trabalho na atenção social, especialmente no contexto local.

Tais questões nos levaram a buscar formas de aproximação mais estreitas entre aquilo que se faz no âmbito da formação universitária com o trabalho de profissionais nos serviços, no sentido do que é sinalizado por Amendola (2014), de buscar uma formação não utilitarista que considere demandas sociais e ética na preparação de estudantes para os desafios e dilemas no cotidiano de práticas. Como princípio inicial para o planejamento da proposta, tínhamos o entendimento da universidade pública como espaço de promoção de uma política educacional que deve fazer interface e operar de forma conjunta com as 
demais políticas públicas. Como forma de operacionalização desse princípio, a ideia e o desejo de minar a bolha universitária tradicionalmente composta por docentes e discentes, incluindo no contexto cotidiano de formação de estudantes pessoas diretamente implicadas naquilo que é abordado pelo currículo.

Com o foco na política de assistência social já delimitado, era preciso definir quem seriam os(as) parceiros(as) a compor esse ambiente híbrido. Logo pensamos em psicólogos(as) vinculados(as) à PNAS, mas muito rapidamente nos perguntamos por que restringir a esses(as) profissionais já que a política, assim como a proposta político-pedagógica do curso de psicologia, enfatiza a formação e o trabalho interdisciplinares. O público-alvo definiu-se então como trabalhadores(as) da PNAS: psicólogos(as) e assistentes sociais.

A questão, agora, era como trabalhar os componentes curriculares de uma disciplina do sétimo período da graduação de psicologia com a participação contínua e horizontal de pessoas não vinculadas ao curso, que não tinham necessariamente formação ou aproximação com o campo disciplinar, promovendo um espaço de formação simultâneo para acadêmicos(as) e trabalhadores(a) da PNAS. Com isso pretendíamos, por um lado, enriquecer a formação acadêmica e a produção de conhecimentos em psicologia, agregando a experiência e os saberes produzidos nos serviços; e, por outro, provocar uma contrapartida da universidade para a sociedade pela socialização e compartilhamento dos conhecimentos aí gerados.

A proposta se delineava, portanto, a partir da compreensão de um projeto de universidade que articula as dimensões política e epistemológica e busca expandir seu alcance para além daqueles formalmente vinculados a ela, afirmando um compromisso de contribuição da universidade com a sociedade. $\mathrm{Na}$ busca por maneiras de operacionalizar o trabalho, a prática da extensão universitária, pensada como uma relação dialógica entre discentes, docentes e profissionais, se apresentou como um caminho possível e instigante (Incrocci \& Andrade, 2018).

Além disso, foram consideradas as orientações encontradas na Política Nacional de Formação Permanente do Sistema Único de Assistência Social (SUAS), no sentido de compor um espaço político-pedagógico interdisciplinar e não hierarquizado de troca de experiências e saberes a partir dos contextos de trabalho (Ministério do Desenvolvimento Social e Combate à Fome [MDS], 2013). Desde o momento inicial de elaboração da proposta, a ideia de troca e construção conjunta de saberes em contraposição à noção de transferência de conhecimentos foi um balizador do trabalho (Fraga, 2017). Assim, buscando coerência com essa premissa, a elaboração e execução da proposta assumiu o caráter de planejamento coletivo, conforme detalharemos a seguir.

\section{O processo de planejamento e execução coletiva}

Em 2018, excepcionalmente, houve a oferta de duas turmas simultâneas da disciplina Intervenções Psicológicas em Processos Socioculturais. Tal circunstância oportunizou a participação de duas docentes na proposição de um trabalho que envolveu, em sua primeira edição, vinte estudantes de graduação em psicologia, quatorze trabalhadoras da política de assistência social (psicólogas e assistentes sociais), e uma estudante de pós-graduação em psicologia em atividade de estágio docência.

Após discussão em torno das questões previamente apresentadas, as docentes contataram as coordenações dos Centros de Referência de Assistência Social (Cras) e dos Centros de Referência Especializados de Assistência Social (Creas) do município. Nesse contato apresentou-se às gestoras a proposta de, no âmbito da disciplina curricular do curso de Psicologia, ofertar vagas para trabalhadores(as) da PNAS com as finalidades de promover diálogos e trocas de saberes entre profissionais vinculadas à política de assistência social e acadêmicos(as) do curso de Psicologia; desenvolver metodologias dialógicas de ensino aprendizagem sobre a realidade social local e a PNAS; e refletir criticamente sobre os processos de intervenção psicossociais.

A participação de profissionais seria formalizada mediante projeto de extensão, na modalidade curso de atualização, com carga horária mínima de 30 horas, conforme definido pelas normas da extensão universitária. Tal perspectiva encontrava amparo na proposta institucional de curricularização das ações de extensão, em consonância com as diretrizes do Ministério da Educação (MEC) para a realização de atividades de extensão no ensino superior, que em seu artigo $3^{\circ}$ a caracteriza como:

atividade que se integra à matriz curricular e à organização da pesquisa, constituindo-se em processo interdisciplinar, político educacional, 
cultural, científico, tecnológico, que promove a interação transformadora entre as instituições de ensino superior e os outros setores da sociedade, por meio da produção e da aplicação do conhecimento, em articulação permanente com o ensino e a pesquisa (MEC, 2018, s/p).

Obtidas a anuência e o apoio institucional da Semas, iniciou-se o processo de discussão da proposta com as turmas de estudantes, quando buscou-se pactuar um comprometimento conjunto com um projeto que embora sinalizasse muitas potencialidades, sabíamos trazer consigo vários desafios e incógnitas. Um dos desafios iniciais era que a perspectiva de elaboração e gestão coletiva de seu desenvolvimento demandava uma temporalidade e uma lógica pedagógica diferentes das instituídas nos espaços de ensino-aprendizagem tradicionais. Essa questão foi amplamente discutida com a turma de estudantes, em particular nos dois encontros iniciais, e diante da disponibilidade e engajamento discente para assumir conjuntamente a realização dos trabalhos - mesmo que isso significasse, naquele momento, incertezas sobre sua operacionalização -, seguimos adiante.

O próximo passo no estabelecimento da parceria de trabalho foi uma reunião realizada na sede da Semas, convocada pelas gestoras inicialmente contatadas, que contou com a participação de psicólogos(as), assistentes sociais e educadores(as) vinculados à PNAS, representantes de estudantes e docente da disciplina. Nessa reunião colocou-se em discussão a proposta e, diante da manifestação de interesse dos(as)s trabalhadores(as), foram acolhidas sugestões sobre seu desenvolvimento, objetivos, questões e temas a serem abordados e até o título que o curso de extensão deveria receber.

Essas três etapas de apresentação e negociação da proposta envolvendo docentes, gestoras, estudantes e trabalhadores(as) foram fundamentais no estabelecimento dos princípios balizadores do trabalho: horizontalidade, processualidade, cogestão, coparticipação, corresponsabilização e construção conjunta de saberes na interface serviços e universidade.

$\mathrm{Na}$ sequência, considerando-se o caráter de abordagem prática de projetos de intervenção da disciplina na qual a proposta tomou forma, foram realizados seis encontros com a participação apenas de discentes e docentes, para um planejamento preliminar das atividades. Destacamos dois objetivos principais desses encontros: a) aproximar os(as) estudantes das noções básicas da PNAS, como história, leis, normas operacionais e conceitos, na medida em que os diálogos posteriores seriam com pessoas inseridas na política de assistência social e a turma não tinha familiaridade com tais questões; e b) trabalhar, do ponto de vista da formação acadêmica, o processo de elaboração de um projeto de intervenção psicossocial, considerando-se aqui que a própria atividade a ser desenvolvida no âmbito da disciplina, com a participação de trabalhadores(as) da PNAS, configurava-se com uma intervenção, tanto no contexto da formação como dos serviços.

Essa etapa do planejamento, em especial o segundo objetivo, permitiu que mesmo diante dos princípios de construção coletiva da proposta entre todos os segmentos envolvidos, não se perdesse de vista a responsabilidade da universidade como sua proponente e sediadora. Uma proposta horizontal não significaria uma proposta sem coordenação e, nesse sentido, discentes foram desafiados(as) a assumir um protagonismo na preparação dos encontros a serem realizados conjuntamente com profissionais. Além da aproximação com a PNAS, deu-se especial atenção aos aspectos éticos e técnicos do trabalho da psicologia nas políticas públicas e às metodologias de planejamento, execução, avaliação e experiências de intervenção psicossocial.

As atividades de extensão com a participação dos(as) trabalhadores(as) da assistência social começaram apenas após essas etapas iniciais. A partir de então foram realizados oito encontros na universidade envolvendo professoras, discentes, psicólogos(as) e assistentes sociais, além de visitas técnicas aos serviços onde trabalhavam esses(as) profissionais.

Os encontros realizados na universidade, nos horários regulares da disciplina curricular, eram coordenados de maneira conjunta por estudantes, trabalhadores(as) e docentes e abordavam temas e problemáticas da interface da PNAS previamente definidos por esse coletivo. Para cada encontro, estimulava-se a oferta de materiais para leitura prévia (de textos acadêmicos a documentos da própria política), bem como o desenvolvimento de atividades com caráter dialógico que permitissem o intercâmbio das experiências e saberes de profissionais, estudantes e discentes.

Por decisão do grupo, a cada encontro realizava-se também um café da manhã coletivo em que, muito além dos alimentos, compartilhava-se afetos 
e construía-se aproximações entre o grupo de estudantes anfitriões(ãs) e profissionais convidados(as) posição que era invertida quando a turma de estudantes visitava os serviços. Ao final de cada encontro discutia-se, numa breve avaliação, o prosseguimento do trabalho para a semana seguinte, fazendo coletivamente os ajustes considerados necessários.

Dos encontros nos serviços participaram apenas os discentes e profissionais, por limitações impostas às docentes naquele momento por sua carga de atividades. Tais encontros foram organizados, inicialmente, com a divisão da turma em pequenos grupos compostos necessariamente por um(a) ou dois(duas) profissionais e até cinco estudantes. Essa divisão foi pensada para constituir um processo de acolhimento mútuo de estudantes a profissionais, quando na universidade, e de profissionais a estudantes, quando nos serviços. Tal organização também buscava viabilizar o trabalho com um grupo que naquele momento excedia 30 participantes. Em momentos posteriores, na realização dessa mesma proposta com turmas menores, outras estratégias foram adotadas, como a circulação de estudantes por todos os serviços onde estavam lotados(as) os(as) trabalhadores(as). O número de visitas técnicas realizadas, bem como as atividades acompanhadas nessas visitas, foi acordado entre profissionais e estudantes considerando, sobretudo, questões técnicas e éticas do serviço, mas também a disponibilidade de horários dos(as) envolvidos(as).

Ao final do projeto, como atividade de encerramento, realizou-se um encontro de avaliação na universidade, onde foram apresentadas e discutidas as potencialidades e dificuldades da realização da proposta, bem como levantamento de sugestões para continuidade do trabalho. Em um momento posterior houve uma reunião de retorno das docentes com a gestora que acabou por se constituir o vínculo principal com a Semas, ocasião em que renovou-se a disponibilidade mútua para dar prosseguimento ao trabalho.

Diante do desejo de continuidade expresso principalmente por estudantes e profissionais, um desdobramento importante foi a ampliação dessa modalidade de trabalho de integração da universidade com o serviço na disciplina consecutiva à que deu início a essa proposta (a disciplina Temáticas Contemporâneas em Processos Socioculturais), bem como a formalização de campos de estágio junto aos serviços da PNAS.
Aementa da disciplinaTemáticasContemporâneas em Processos Socioculturais prioriza a oferta de elementos conceituais e instrumentais sobre temas referentes às questões socioculturais, além de pretender se articular às práticas e experiências de estágios obrigatórios. O modo como os encontros foram conduzidos variavam a cada ano, o que reforçava seu caráter experimental e a necessidade de ajustá-lo de acordo com a turma e com os(as) profissionais que dela participassem. Em uma das experiências, inspirados(as) no próprio nome da disciplina, optamos por abordar temáticas contemporâneas que dissessem respeito ao momento político vivenciado a partir das eleições e da posse, em janeiro de 2019, de um presidente de ultradireita. Propunha-se não somente analisarmos o contexto sociopolítico e o novo cenário que se abria e que afetava o cotidiano dos serviços como também e sobretudo - os afetos que a entrada numa onda neoconservadora suscitava em todos(as) nós a partir dos diferentes lugares que ocupávamos. Os encontros tiveram como espinha dorsal o tema democracia e, com ele, emergiram os subtemas que apareciam frequentemente nos noticiários cotidianos e nas pautas governamentais: aborto, "ideologia" de gênero, laicidade e fundamentalismo religioso, escola sem partido, populações indígenas, desmatamento, dentre outros.

Nessas experiências, manteve-se a universidade como espaço primordial dos encontros, o que permitiu o retorno de trabalhadores(as) a esse espaço. Era na universidade que ocorriam os encontros semanais envolvendo estudantes, professoras e profissionais. Profissionais avaliaram como um aspecto positivo da proposta o fato de poderem deslocar-se dos serviços para estarem na universidade dedicando-se outra vez a estudar, assim como vivenciou-se de forma positiva a frequência de discentes aos serviços. Contudo, entendemos que seria enriquecedor um trabalho itinerante pelos serviços com todo o coletivo envolvido. Tal ideia chegou a ser ponderada, porém, esbarramos na limitação de poder, naquele momento, conciliá-la com outras demandas direcionadas às docentes pela universidade e com as dificuldades de mobilidade na cidade, que tornavam o tempo de deslocamento um fator impeditivo.

Ao final da disciplina de Temáticas, contudo, os(as) profissionais sentiram necessidade de levar tais discussões para os serviços, o que proporcionou a criação de uma extensão não mais vinculada às disciplinas. Isso tem possibilitado, atualmente, a construção de uma itinerância, na qual discentes e 
docente passaram a ser levados(as) com transporte da própria Assistência para os serviços, reunindo-se a cada encontro em um Cras ou Creas de diversas regiões do município. Num primeiro momento, foram realizadas reuniões com os(as) profissionais visando levar tais temas para as equipes dos serviços envolvidos. A ideia central é produzir discussões que se conectem com os retrocessos e perdas de direitos que afetam diretamente os(as) usuários(as) que acessam os equipamentos da assistência, além de politizar o cotidiano de atendimento não somente de técnicos(as) como também da equipe administrativa. A partir de eixos como gênero, democracia e direitos humanos, pretende-se desalinhar certezas e produzir multiplicadores(as) capazes de lidar com as complexidades que este tipo de trabalho suscita.

A itinerância, neste caso, também produz desalinhamentos no próprio cotidiano de discentes e docente, ao colocar seus corpos em territórios desconhecidos, convidando-nos ao exercício de construção coletiva e muitas negociações. Nesse sentido, o trabalho de discentes e docentes a partir dessa itinerância conecta-se com a ideia de "pesquisar com os pés" (Mendes, Azevedo, \& Frutuoso, 2019). Pesquisar com os pés significa conhecer outros territórios existenciais, desarvorando saberes pré-fabricados. Parte-se da ideia trazida por François Tosquelles, ${ }^{1}$ que enfatiza que, ao andarmos, o fazemos com os pés, e não com a cabeça. Seriam os pés os grandes leitores do mundo. Habitar outros territórios, estranhá-los e entranhá-los em nosso universo acadêmico, pensar com o corpo todo imerso em outras paragens, desenhar mapas nos pés que permitem o confronto com o aconchego das cadeiras firmemente coladas nas salas de aula. Problematizar, assim, saberes disciplinados: da passividade das aulas que são transmitidas ano após ano, dos corpos em repouso dentro das universidades, da verticalização do conhecimento.

As equipes que nunca participaram dessa experiência também serão convidadas a construírem conosco conhecimentos capazes de produzirem sensibilidades outras em meio às maciças perdas de direitos às quais estão expostas não somente a população atendida no território. Essas perdas dizem respeito a todas(os) nós, pois impactam, de maneira singular, em nossos gestos diários.

\section{Contribuições para uma formação integrada aos serviços}

O espaço universitário, como lugar privilegiado de construção de saberes e também de crítica social, tem sido questionado sobre sua capacidade de diálogo com o "mundo real". Como resposta, acadêmicos(as) têm buscado afirmar e efetivar a universidade como um locus de produção de um conhecimento conectado com as problemáticas locais. É significativo, por exemplo, o movimento de pesquisadores(as) na afirmação de posicionamentos políticos-epistemológicos vinculados a suas práticas de investigação. Porém, ainda precisamos amadurecer a oferta de uma formação de graduação e criar outras estratégias políticopedagógicas que permitam a ampliação desse diálogo.

Por sua vez, a Política Nacional de Educação Permanente do SUAS explicita a necessidade da promoção de ações de formação interdisciplinares, historicizadas e significativas (MDS, 2013). A aprendizagem significativa diz respeito à construção de conhecimentos a partir de saberes e experiências prévias dos sujeitos (MDS, 2013). Para que ela ocorra, entendemos ser necessária, além de conteúdos e competências teóricas, a promoção de condições socioafetivas para o compartilhamento desses saberes e experiências.

A consideração desses aspectos oriundos das universidades e dos serviços perante as demandas da sociedade, convergiu para a proposição dessa experiência de formação integrando acadêmicos(as) e profissionais da PNAS. Iniciada no segundo semestre de 2018, a proposta teve continuidade em outras disciplinas e atividades, e semestralmente na mesma disciplina inicial em turmas posteriores, mantendo-se os princípios balizadores e modificando-se estratégias e metodologias de trabalho de acordo com o tamanho das turmas, interesses, experiências e inserções dos(as) participantes, bem como aprendizagens emergentes desse processo.

Fazer diferente do que se faz, embora soe bastante instigante, muitas vezes coloca-nos diante de dúvidas; uma das primeiras que encontramos foi como estruturar os encontros e as questões a serem trabalhadas. A decisão do coletivo geralmente tem sido a eleição conjunta de temas que fazem interface com a PNAS e com a psicologia, que são organizados para o debate a cada encontro, trazendo-se para isso subsídios

${ }^{1}$ Laboratório de Sensibilidades. (19 jun. 2019). Pensar com os pés. Vídeo com François Tosquelles. [Vídeo]. https://laboratoriodesensibilidades.wordpress.com/2019/06/19/pensar-com-os-pes-video-com-francois-tosquelles-1-minuto-com-legendas/. 
teóricos (definidos com a participação bastante ativa dos(as) estudantes sob supervisão docente) e experiências práticas.

Um dos pontos que tomamos como bastante expressivo e relevante do trabalho realizado foi a explicitação de uma grande demanda pelo estudo de temas como: relações e violências de gênero, questões étnico-raciais, produção e gerenciamento da pobreza e da vulnerabilidade, concomitantemente com a discussão da própria PNAS e de direitos sociais.

Costa (2017) discute a preponderância de mulheres e pessoas negras como usuárias das PNAS e de um distanciamento dessas discussões no cotidiano dos serviços, ausência também recorrentemente expressa pelos(as) profissionais que nos acompanharam. Do mesmo modo apresentou-se a necessidade de estudo sobre os impasses em relação ao atendimento da população LBGTIA+ pelos serviços da política de assistência social, como discutido por Barbosa, Silva e Ribeiro (2018).

Essas lacunas não podem ser situadas apenas para profissionais nos serviços, mas constituem-se em deficiências que necessitam de revisão nos próprios currículos acadêmicos dos cursos de psicologia diante da realidade de racialização e generificação da pobreza. A convergência da experiência de estudantes e profissionais diante de um "não saber" ou um "não saber como ou o que fazer" frente a essas questões, permitiu uma sensibilização para a relevância de seu estudo e debate tanto no ambiente acadêmico como nos serviços, que ficou expressa, dentre outras formas, pelo convite feito por trabalhadores(as) para que estudantes participassem com eles(as) de rodas de conversa sobre temas como gênero e racismo nos serviços.

Outro elemento que merece destaque foi a identificação da ausência de aproximações prévias dos(as) estudantes com a política de assistência social no âmbito da graduação em psicologia. Embora já próximo ao final do curso, que tem duração de 10 semestres, e em um contexto onde muitos(as) dos(as) estudantes e suas famílias são beneficiários(as) de programas vinculados à PNAS, a maioria dos(as) estudantes afirmou não conhecer a política ou nunca haver estudado durante o curso de psicologia. Consequentemente, também afirmavam desconhecer seus princípios e muitos de seus conceitos básicos como noções de vulnerabilidade, pobreza, direitos sociais, autonomia, entre outras. Nesse sentido, buscou-se facilitar a aproximação com a produção acadêmica contemporânea sobre essas temáticas, bem como orientar sobre o acesso à legislação, a normas operacionais e técnicas e a referências para o trabalho da psicologia na assistência social. Para isso, foram bastante importantes, além dos artigos acadêmicos publicados em periódicos da área, as coletâneas recentes que reúnem pesquisas e debates sobre a inserção da psicologia na PNAS, tais como os trabalhos de Cordeiro, Svartman e Souza (2018); Cruz, Guareschi e Battistelli (2019); Fernandes e Hellmann (2016); as referências técnicas publicadas pelo Centro de Referências Técnicas em Psicologia e Políticas Públicas (Crepop) do Sistema Conselhos de Psicologia (CFP e CRPs); entre outros.

A eleição dos temas de trabalho pelo coletivo favoreceu o envolvimento dos(as) participantes nos encontros, bem como o diálogo com o contexto local, que pode assim ocorrer de maneira sempre permeada pela análise dos aspectos social, cultural, político e econômico da região onde se situam universidade e serviços. Desse modo, a inserção da psicologia na política de assistência social e suas interfaces com as questões abordadas ganhou materialidade, localidade e historicidade. A presença nas aulas de profissionais da psicologia e serviço social vinculados à PNAS nos levava a uma aprendizagem de conceitos, teorias, legislações e técnicas conectadas com a realidade local: as condições do serviços, as regiões da cidade, as características territoriais de cada bairro, a gestão local da política, as formas de contratação e condições de trabalho de profissionais, suas iniciativas na resolução de problemas e assim por diante. A formação acadêmica encontrava-se com a vida nos e dos serviços/ trabalhadores(as), podendo dialogar com as especificidades, dificuldades, estratégias e potencialidades gestadas localmente. Além dos aspectos técnicos, éticos e teóricos do exercício profissional na política de assistência, estudantes puderam aproximar-se de questões que dizem respeito à própria inserção nesse campo de trabalho, tais como concursos, processos seletivos e remunerações para psicólogos(as).

A metodologia adotada permitiu ainda a resolução do problema inicialmente apontado em relação à abordagem prática de projetos de intervenção. $\mathrm{O}$ espaço da sala de aula, até então circunscrito a um local de ensino-aprendizagem, transmutou-se em espaço de extensão, produção de conhecimentos e realização de ações de intervenção, protagonizadas por estudantes e profissionais. Para os(as) estudantes houve a 
oportunidade do exercício da autonomia e da gestão colaborativa, ao passo que para profissionais, a possibilidade de simultaneamente aprender e compartilhar saberes e experiências em um outro lugar distinto dos serviços. Aliou-se, desse modo, aspectos da formação profissional, tanto de estudantes de graduação como de trabalhadores(as) - psicólogos(as) e assistentes sociais -, com a produção de conhecimento em psicologia voltada ao trabalho nas políticas públicas.

Outra escolha que marcou significativamente $o$ trabalho foi a opção de oferecer vagas na modalidade extensão não apenas para profissionais da psicologia vinculados(as) à PNAS, mas também para assistentes sociais. Essa abertura para o diálogo interdisciplinar foi demarcada desde o início da construção da proposta e chegou, em um momento inicial, a causar questionamentos da gestora em relação a seus objetivos e viabilidade. Coube-nos, então, sustentar a relevância dessa interlocução tanto para estudantes em formação como para profissionais já inseridas(os) nos serviços, diante da necessidade de olhares mais complexos para as problemáticas comuns encontradas no cotidiano de trabalho. Além disso, como preconiza a própria política, tais profissionais devem atuar de forma conjunta e interdisciplinar, aspecto frequentemente mencionado, porém poucas vezes efetivamente exercitado, especialmente durante o período de formação profissional, em cursos marcadamente organizados pela lógica disciplinar. O compartilhamento das experiências e saberes ao longo do processo permitiu a identificação e construção de vínculos entre as práticas de cada profissional, explicitando-se, quando necessário, as especificidades, mas também borrando-se fronteiras quando elas perdiam o sentido diante das situações apresentadas.

As avaliações, tanto da experiência políticopedagógica em curso como dos(as) estudantes (parte dos rituais de formação acadêmica), foram realizadas considerando-se não os produtos finais, mas o processo. Assim, contemplou momentos de avaliação coletiva e dialógica e também momentos de autoavaliação, relativamente a implicações, crescimentos e aprendizagens vivenciadas.

Em termos de dificuldades, talvez a mais significativa tenha sido lidar com a temporalidade da congestão e com o manejo do imprevisível, questões exacerbadas pelo trabalho com dois grupos que tinham rotinas bastante distintas: estudantes e profissionais. Em um modelo pedagógico centrado no(a) professor(a), torna-se muito mais fácil planejar e realizar as atividades docentes, de modo mais ou menos independente do envolvimento dos(as) estudantes. Na proposta adotada, cada movimento de participação, ausência ou atraso, de estudantes e profissionais, redefinia o que era possível. Cada encontro e seu momento de avaliação nos recolocava questões sobre como seguir e, como docentes, precisamos também aprender como estar nesse outro tempo, respeitando os processos do grupo em momentos em que o víamos afastar-se daquilo que acreditávamos ser melhor. Estudantes angustiados(as) com tanta abertura e responsabilidade, profissionais que muitas vezes não podiam estar presentes por demandas do trabalho e docentes se perguntando sobre como e quando intervir, foram elementos que transversalizaram essa experiência desde seu início.

\section{Entre incertezas e apostas, a invenção}

Em virtude da interiorização da profissão, os serviços socioassistenciais têm sido uma opção pelo aumento cada vez maior de empregabilidade nessa área entre profissionais da psicologia (Lima \& Schneider, 2018). Podemos dizer que há dois sistemas que são estatalmente regulados e que se tornam, via de regra, nossos empregadores mais significativos, a saber: o Sistema Único de Saúde (SUS) e o SUAS (Oliveira \& Costa, 2018). Para essas autoras, inserir-se neste campo implica na diversificação das atividades e práticas psicológicas bem como em debates sobre os direcionamentos ético-políticos de nosso trabalho a partir deste novo público: as pessoas pobres. Na história da nossa profissão não existem narrativas que apontem um trabalho significativo no combate à pobreza (Oliveira \& Costa, 2018). Cabe-nos, então, intensificar a produção de debates inspirados nesse campo de atuação.

Os encontros proporcionados pelas disciplinas de Intervenções e Temáticas mostraram a necessidade de conectar diferentes atrizes e atores que estiveram dispostos(as) a vivenciar uma experiência de completo deslocamento. Por um lado, os(as) trabalhadores(as), que voltaram a ocupar os bancos universitários e que, em diferentes momentos, apontaram o quanto isso significava para eles(as): desde a possibilidade de se inserir novamente nos debates acadêmicos, a necessidade de obter um olhar de fora sobre suas práticas, até a aspiração de retomar os estudos e planejar-se para uma pós-graduação. Por outro, as(os) estudantes, 
que, inserindo-se nos territórios, tiveram a oportunidade, para muitos(as) inédita, de conhecer um equipamento socioassistencial, aproximar-se de famílias, de relatórios técnicos e, em algumas ocasiões, das ambiguidades e contradições que caracterizam a relação do Estado e dos(as) profissionais com os(as) usuários(as) que encontram-se em contextos de brutal desigualdade social. Eles(as) puderam compreender, em alguma medida, as dinâmicas de funcionamento, os programas, projetos, ações e atividades que constituem o dia a dia dos serviços. Por sua vez, significou rever as práticas docentes para as professoras que assumiram no âmbito de uma disciplina curricular uma proposta que, embora tivesse claros princípios e objetivos, não se sabia exatamente como operacionalizar. A incerteza que permeou cada etapa da construção e execução da proposta funcionou como alimento para essa revisão e análise constante do que é o espaço da sala de aula, especialmente numa universidade pública situada numa região com altos índices de desigualdade social.

Aconstrução dessa interconectividade possibilitou atransformação dos processos de produção de conhecimento. Olhares que relembravam a época da graduação, como o dos(as) profissionais, cruzavam-se com olhares de quem jamais tinha visto as coisas acontecendo ao vivo e, muitas vezes, de forma bastante real. A aposta desses encontros esteve no entrecruzamento dessas miradas, das surpresas decorrentes delas, das torções provocadas a partir da circulação de corpos, saberes e afetos pelos espaços extramuros da universidade e pela (des)hierarquização de lugares ocupados dentro da sala de aula. Indagações que costuraram os encontros e que ainda perduram, nos desdobramentos dessa experiência inicial - têm sido as seguintes: como produzir vínculos? (com as(os) usuárias que acessam os serviços e também com as(os) profissionais que estão conosco em sala de aula ou em campo de estágio). Como conduzir processos horizontais? Fazer com é possível? Em quais circunstâncias? É possível construir coletivamente e de maneira horizontal o tempo todo? E como ficam os protocolos, prazos ou a necessidade de encaminhar e decidir as coisas rapidamente? Como abrir mão dos gestos tradicionais, desmanchar as fronteiras que a todo tempo se interpõem e que seduzem pela familiaridade e que, às vezes, dão agilidade aos processos? Como compreender que todos(as) são potenciais produtores(as) de conhecimento sobre a realidade social e trazer esses conhecimentos para juntarem-se aos nossos e, talvez, modificá-los? Seria possível, um dia, a ampliação dessa experiência para a inclusão de usuários(as) nesse espaço de entrelaçamento de universidade e serviços?

Os encontros possibilitaram experimentar a complexidade das situações. Para estudantes, profissionais e docentes, ter que gerir um espaço coletivo de maneira dialogada e compartilhada resultava em criar articulações entre o que acontecia dentro da sala de aula e tinha relações com as práticas e fazeres realizados no cotidiano dos serviços. Às vezes isso ficava visível quando um(a) profissional conduzia o encontro oferecendo-nos uma palestra, prática que produzia binarismos, criava distâncias entre aqueles(as) que têm o saber e aqueles(as) que não têm. Esse tipo de fazer era replicado quando estavam em contato com usuários(as)? Em análise de Cordeiro (2018) sobre o trabalho da psicologia na assistência, a modalidade palestra é uma das mais acionadas por psicólogos(as) que atuam no SUAS. Práticas tradicionais repetidas até a exaustão, provavelmente reproduções daquilo que aprenderam em sala de aula, conosco, durante toda a formação.

No caso dos(as) estudantes, o desafio de sair do lugar de passividade e assumir a gestão dos encontros foi um tema recorrente, sobretudo na continuidade da extensão, na disciplina de Temáticas. Essa tarefa nem sempre foi fácil. Frequentemente, a turma dizia o quanto tinha sido difícil conduzir a disciplina, os encontros. Era muito mais simples chegar na sala e ter tudo já delimitado pelas docentes. Alguns(mas) desanimavam, sentiam-se dentro de um caos, mas com o passar dos meses compreendiam que as apostas iniciais e sua construção tinham sido exitosas: tudo parecia estar funcionando. Parecia tão fácil, no final das contas, mas não era. Tratava-se do resultado de um investimento que vinha acontecendo há meses. Se era complexo fazer com em sala de aula, entre pessoas conhecidas e com objetivos comuns, no ambiente protegido da universidade, como seria construir um projeto singular ouvindo as vozes de usuários(as) e respeitando sua alteridade, muitas vezes na condição de profissionais com vínculos precarizados de trabalho?

E para nós, docentes, como era vivenciar este lugar, também de deslocamento, em que dividíamos o protagonismo com pessoas tão diferentes de nós, compartilhávamos com elas a condução do processo pedagógico, dependíamos delas, de alguma maneira, para que ele desse certo? Sustentar a angústia de embarcar em uma prática que, durante muitos momentos, 
não se sabia qual destino teria, quais seus contornos e se alcançaríamos nossos objetivos? Sustentar os receios dos(as) estudantes, mas também o entusiasmo de todo o grupo. Abrir mão, pode-se dizer, de um roteiro prévio, da escolha dos textos que comporiam o conteúdo programático e mesmo dos debates a serem priorizados. De certa forma, desvencilhar-se de um lugar e das inúmeras prescrições que se colam a ele, era o exercício que tínhamos que fazer continuamente.

Para todos(as) nós, a experiência implicou em abandonar itinerários conhecidos de antemão, desburocratizar a existência e investir nas potencialidades dos encontros, no face a face das relações e na confiança de que elas seriam construídas a partir do respeito a nossas singularidades. Na verdade, podemos dizer que se tratou de performar em sala de aula sentires, fazeres e práticas que acontecem, todos os dias, nos cenários da Política de Assistência Social e em outras políticas públicas, uma vez que é sempre disto que estamos falando: escutar sensivelmente o outro, compartilhar conhecimentos, convidar para caminhar junto, inventar e sustentar tudo o que pode acontecer durante uma travessia. Tais ações não estão disponíveis em um receituário (neste caso, pedagógico). Elas implicam em inúmeras negociações sobre as maneiras mais apropriadas, ao menos para aquele momento, de participar do processo em pé de igualdade e considerando a heterogeneidade daquelas(es) que se encontram ali incluídos(as).

Nessa experiência, pode-se produzir uma outra relação ética entre os(as) agentes envolvidos(as), como fomentar a horizontalização da relação da universidade com os serviços, buscando romper com o olhar crítico-avaliativo muitas vezes lançado desde a universidade sobre aqueles, particularmente na realização de estágios e visitas técnicas. O que era visto e mobilizado nas visitas técnicas era discutido em nossos encontros na universidade, com a participação dos(as) profissionais.
Apesar dos desafios impostos pelo processo de construção e operacionalização da proposta apresentada, as avaliações realizadas em cada uma de suas edições nos permitem afirmar que ela proporcionou para os(as) envolvidos(as) relevantes reflexões sobre a importância da qualificação e da politização das práticas de ensino-aprendizagem da psicologia e do exercício profissional de psicólogos(as) e assistentes sociais inseridos(as) na política de assistência social. A dinâmica de trabalho adotada exigiu uma modificação radical na postura de docentes, discentes e profissionais no processo de troca de experiências e saberes, bem como o estabelecimento de uma outra relação universidade-serviços. Ela permitiu a construção de enfoques mais complexos sobre os contextos de produção de conhecimento e de intervenção, especialmente sobre a psicologia e o trabalho em territórios e com populações vulnerabilizadas e negligenciadas pelo Estado. A avaliação da experiência realizada nos permite afirmar que é possível fazer da sala de aula um espaço de compartilhamento de práticas e saberes, integrado aos campos de exercício profissional, com a criação de processos de aprendizagem contra-hegemônicos às perspectivas tradicionais, fazendo de discentes e profissionais copartícipes de sua própria formação.

Para concluir, ressaltamos que apresentamos aqui alguns dos elementos que poderíamos chamar de mais significativos dessa experiência, com o intuito de, ao compartilhar, contribuir com a proposição de outras experiências políticopedagógicas. O detalhamento de todo o processo teve como objetivo explicitar o caráter processual e de construção dessa experiência, seus acertos e equívocos, reforçando seu caráter de experimentação, que repercute tanto na formação de estudantes de psicologia como nas práticas profissionais de psicólogos(as) e assistentes sociais inseridos(as) nos serviços.

\section{Referências}

Amendola, M. F. (2014). Formação em psicologia, demandas sociais contemporâneas e ética: Uma perspectiva. Psicologia: Ciência e Profissão, 34(4), 971-983. https://doi.org/10.1590/1982-370001762013

Arias, P. G. (2010). Corazonar el sentido de las epistemologías dominantes desde las sabidurías insurgentes, para construir sentidos otros de la existencia. CALLE14: Revista de Investigación en el Campo del Arte, 4(5), 80-95.

Barbosa, K. S., Silva, P. M. G. da, \& Ribeiro, J. K. A. (2018). “Entre amores e dissabores”: A política de assistência social voltada aos/às LGBTs. Temporalis, 18(36), 239-255. https://doi.org/10.22422/temporalis.2018v18n36p239-255 
Bernardino-Costa, J., Maldonado-Torres, N., \& Grosfoguel, R. (Orgs.). (2019). Decolonialidade e pensamento afro-diaspórico. Autêntica Editora.

Cordeiro, M. P. (2018). A psicologia no SUAS: Uma revisão de literatura. Arquivos Brasileiros de Psicologia, 70(3), 166-183.

Cordeiro, M. P., Svartman, B., \& Souza, L. V. (Orgs.). (2018). Psicologia na Assistência Social: Um campo de saberes e práticas. Instituto de Psicologia.

Costa, G. (2017). Assistência Social, no enlace entre a cor e gênero dos(as) que dela necessitam. O Social em Questão, 20(38), 227-246.

Cruz, L. R. C. da, Guareschi, N., \& Battistelli, B. M. (Orgs.). (2019). Psicologia e assistência social: Encontros possíveis no contemporâneo. Vozes.

Fernandes, R. M. C., \& Hellmann, A. (Orgs.). (2016). Dicionário crítico: Política de assistência social no Brasil. Ed. UFRGS.

Fraga, L. S. (2017). Transferência de conhecimento e suas armadilhas na extensão universitária brasileira. Avaliação: Revista da Avaliação da Educação Superior, 22(2), 403-419. https://doi.org/10.1590/ S1414-40772017000200008

Incrocci, L. M. de M. C., \& Andrade, T. H. N. de. (2018). O fortalecimento da extensão no campo científico: Uma análise dos editais ProExt/MEC. Sociedade e Estado, 33(1), 187-212. https://doi.org/10.1590/s0102-699220183301008

Lima, F. C., \& Schneider, D. R. (2018). Características da atuação do psicólogo na Proteção Social Especial em Santa Catarina. Psicologia: Ciência e Profissão, 38(2), 347-362. https://doi.org/10.1590/1982-3703001402017

Mendes, R., Azevedo, A. B., \& Frutuoso, M. F. P. (Orgs.). (2019). Pesquisar com os pés: Deslocamentos no cuidado e na saúde. Hucitec; Fapesp.

Mignolo, W. D. (2008). Desobediência epistêmica: A opção descolonial e o significado de identidade em política. Cadernos de Letras da UFF, Dossiê Literatura, língua e identidade, (34), 287-324.

Ministério da Educação. (19 dez. 2018). Resolução n. 7, de 18 de dezembro de 2018. Estabelece as Diretrizes para a Extensão na Educação Superior Brasileira e regimenta o disposto na Meta 12.7 da Lei no 13.005/201. Diário Oficial da União.

Ministério do Desenvolvimento Social e Combate à Fome. (2013). Política Nacional de Educação Permanente do SUAS (1 $1^{\text {a }}$ ed.).

Oliveira, I. F., \& Costa, A. L. (2018). Psicologia e política social: história e debate. In M. P. Cordeiro, B. Svartman \& L. V. e Sousa (Orgs.), Psicologia na Assistência Social: Um campo de saberes e práticas (pp. 32-44). Instituto de Psicologia.

\section{Simone Maria Hüning}

Doutora em Psicologia pela Pontifícia Universidade Católica do Rio Grande do Sul (PUCRS), Porto Alegre - RS, Brasil. Docente e pesquisadora do Programa de Pós-Graduação em Psicologia da Universidade Federal de Alagoas (Ufal), Maceió - AL, Brasil. Bolsista Produtividade 2 CNPq.

E-mail: simone.huning@ip.ufal.br

(1) https://orcid.org/0000-0001-8080-7733

\section{Érika Cecília Soares Oliveira}

Doutora em Psicologia pela Universidade Estadual Paulista (Unesp/Assis), Assis - SP, Brasil. Professora vinculada ao Programa de Pós-Graduação em Psicologia da Universidade Federal de Alagoas (Ufal), Maceió - AL, Brasil. Docente do Departamento de Fundamentos Pedagógicos da Universidade Federal Fluminense (UFF), Niterói - RJ, Brasil.

E-mail: erikaoliveira@id.uff.br

(1) https://orcid.org/0000-0003-4877-0971

Endereço para envio de correspondência:

Universidade Federal de Alagoas. Av. Lourival Melo Mota, S/N, Tabuleiro do Martins. CEP: 57072-900. Maceió AL. Brasil. 
Recebido 14/02/2020

Aceito 29/03/2021

Received $02 / 14 / 2020$

Approved 03/29/2021

Recibido $14 / 02 / 2020$

Aceptado 29/03/2021

Como citar: Hüning, S. M., \& Oliveira, É. C. S. (2022). Contribuições para uma formação em psicologia integrada à Política de Assistência Social. Psicologia: Ciência e Profissão, 42, 1-13. https://doi.org/10.1590/1982-3703003234060

How to cite: Hüning, S. M., \& Oliveira, É. C. S. (2022). Contributions to the formation in psychology integrated to the Social Assistance Policy. Psicologia: Ciência e Profissão, 42, 1-13. https://doi.org/10.1590/1982-3703003234060

Cómo citar: Hüning, S. M., \& Oliveira, É. C. S. (2022). Contribuciones a la formación en psicología integrada con la Política de Asistencia Social. Psicologia: Ciência e Profissão, 42, 1-13. https://doi.org/10.1590/1982-3703003234060 